Review

\title{
Review of Microalgae Harvesting via Co-Pelletization with Filamentous Fungus
}

\section{Sarman Oktovianus Gultom and Bo $\mathrm{Hu}$ *}

Department of Bioproducts and Biosystems Engineering, University of Minnesota, 1390 Eckles Ave., MN 55108, USA; E-Mail: gulto002@umn.edu

* Author to whom correspondence should be addressed; E-Mail: bhu@umn.edu;

Tel.: +1-612-625-4215; Fax: +1-612-624-3005.

Received: 9 October 2013; in revised form: 4 November 2013 / Accepted: 5 November 2013 /

Published: 12 November 2013

\begin{abstract}
Cultivation of microalgae to utilize $\mathrm{CO}_{2}$ and nutrients in the wastewater to generate biofuel products is a promising research objective. However, the process faces tremendous technical difficulties, especially the harvest of microalgae cells, an economically challenging step. Several researchers recently reported co-culturing of filamentous fungi with microalgae so that microalgae cells can be co-pelletized in order to facilitate the cell harvest. This algae pelletization via the filamentous fungi represents an innovative approach to address both the cost and sustainability issues in algae biofuel production and also has potential with direct commercial applications. This paper reviews the current research status in this area and some possible drawbacks of this method in order to provide some possible directions for the future research.
\end{abstract}

Keywords: microalgae; fungal pelletization; cell harvest; mixed culture

\section{Introduction}

An increasing energy demand and potential fossil fuel depletion have become major concerns for people around the world. Furthermore, climatic changes and global warming possibly caused by the emission of greenhouse gases have become contemporary issues to be solved [1-3]. Renewable energy sources, such as solar, biomass, geothermal, wind, and hydropower, are considered to decrease fossil fuel consumption. Biomass is a renewable, biodegradable, and carbon dioxide $\left(\mathrm{CO}_{2}\right)$-neutral energy source with plenty of resources, for example, agricultural residue and waste, forestry waste, municipal solid 
and industrial waste, terrestrial crops, and aquatic plants [4]. Among all the available biofuel products, bio-diesel, which is generated from oil produced by terrestrial crops, is currently a widely used alternative fuel for transportation. However, limited land availability confines the amount of plant-based oil that can be produced for biodiesel production. Many microalgae and fungi species (e.g., Chlorella vulgaris, Mucor circillenous or Mortierella isabellina) are capable of accumulating a high content of lipids that can be converted to different forms of "drop-in" fuels such as biodiesel [5-7]. Unlike traditional oilseed crops, microalgae show great potential due to their potential applications for industrial $\mathrm{CO}_{2}$ removal, higher photosynthetic efficiency, higher biomass production, faster growth, production of a great variety of metabolites, and capability to grow both in ponds and in fermentation units, thus not requiring precious farmlands and forests $[2,8]$.

Microalgae are microscopic unicellular organisms that have the same characteristics as higher plants. As photosynthetic microorganisms, microalgae are able to use sunlight and assimilate $\mathrm{CO}_{2}$ from the air under natural growth conditions and to convert solar energy into chemical energy [9]. In addition to sunlight and $\mathrm{CO}_{2}$, nutrients, trace metals, and water are also needed for microalgae to grow. They can grow exponentially under variable environmental conditions and the reaction in microalgae cultivation that produces biomass can be formulated as follows [9-12]:

$$
\mathrm{CO}_{2}+\mathrm{H}_{2} \mathrm{O}+\text { nutrients }+ \text { light energy } \rightarrow \text { biomass }+\mathrm{O}_{2}
$$

Producing biofuels from microbial lipids is promising; however, new technical processes must be developed to capitalize on the economically feasible potential of accumulating microbial lipids for biofuel production. In general, several factors must be considered before the cultivation system is chosen, including the microalgae strain, the biological needs of microalgae, the nutrient availability, the climate conditions, the availability of sunlight, water, and $\mathrm{CO}_{2}$, and the desired final product $[1,12]$. In general, microalgae growth occurs in three modes, including under phototrophic (autotrophic photosynthesis), heterotrophic, or mixotrophic conditions. Under phototrophic conditions, the growth of microalgae primarily depends on sunlight and $\mathrm{CO}_{2}$ as the energy and carbon source. Under heterotrophic growth conditions, instead of harvesting light and assimilating $\mathrm{CO}_{2}$ from air, microalgae use organic carbon substrates such as glucose, acetate, and glycerol as their energy source. It was observed that the production of microalgal biomass as well as the lipid content in the microalgal cells under heterotrophic conditions were much higher than those under phototrophic growth conditions [2,13]. Because of the higher cell density achieved under these conditions, the microalgae harvesting costs are lower compared with costs for phototrophic conditions. Mixotrophic growth is a combination of phototrophic and heterotrophic conditions, where some microalgae strains have the capability to combine autotrophic photosynthesis and the heterotrophic assimilation of organic compounds, either simultaneously or sequentially.

Therefore, two processes are gaining momentum in both academia and industry. The first remains lipid accumulation via autotrophic microalgae, although several technical barriers result in an unrealistically high cost for biofuel generated from autotrophic microalgae cultures [14]. The algae cells utilize sunlight, $\mathrm{CO}_{2}$ from air or industry waste sources, and nutrients from wastewater for their cell growth and this utilization has multiple advantages, including potential for biofuel production, $\mathrm{CO}_{2}$ mitigation, and wastewater treatment. The major drawback of autotrophic microalgae cultivation lies in their low final cell concentrations, which is primarily caused by the mutual shading effects that 
limit the microalgae cells' ability to reach high concentrations. Another process to grow microalgae is a two-stage hybrid method using autotrophic and heterotrophic cultivations of microalgae. This method includes cultivating photoautotrophic algae, concentrating cells, and then transferring them to a fermentor for heterotrophic cultivation. During the photoautotrophic cultivation stage, the culture is exposed to a light source, such as sunlight with $\mathrm{CO}_{2}$ obtained from a $\mathrm{CO}_{2}$ source or from air. Organic carbons from agricultural sources are added during heterotrophic cultivation stage. The process was first patented and its algae ( $C$. protothecoides) biomass concentration reached to $108 \mathrm{~g} / \mathrm{L}$ with lipid content at approximately $52 \%$ of dry cell weight, one of the highest overall productivities ever reported in the microalgae biodiesel production field [15]. This approach combines merits from both autotrophic and heterotrophic cultivations; while it may not be significantly more efficient than the heterotrophic culture alone. The final algae cells mostly come from the heterotrophic cultivation. The stage of autotrophic cultivation may only have a very limited contribution in the overall cell biomass accumulation and it may pose challenges for possible contaminations to the heterotrophic cultivation.

\section{Harvesting Methods of Microalgae}

Autotrophic algae culture is especially promising and ideal, but the algae cell harvest from cultivation broth has always been one of the major obstacles for the algae-to-fuel approach. Since microalgae cells have specific characteristics such as a low density (typically in the range of $0.3-5 \mathrm{~g} / \mathrm{L}$ ) and a small size (typically in the range of 2-20 $\mu \mathrm{m}$ ), they are technically challenging to harvest. A number of harvesting techniques have been applied, such as flotation, gravity and centrifugation sedimentation, flocculation and ultrasonic aggregation, and filtration, as well as a combination of these techniques. The method used to harvest microalgae cells is dependent on the characteristics of the microalgae, such as size and density [16]; harvesting also usually requires a separate step after the cell cultivation. All of the available harvest approaches are only economically feasible for production of high-value products [17] and thus have limitations for effective, cost-efficient production of biofuel [18]. A brief discussion of the most common harvesting methods is included here.

\subsection{Flotation}

The flotation method is a gravity separation process in which the microalgal cells attach to air or gas bubbles and accumulate as float, which can be skimmed off. For some microalgal strains, natural float occurs at the surface of the water when their lipid content increases. In addition, in most cases flocculants are also applied for effective flotation [19]. Various flotation processes are based on the method of bubble production: dissolved air flotation (DAF), electrolytic flotation, and dispersed air flotation [18]. DAF is a process in which small bubbles are generated $(10-100 \mu \mathrm{m})$, which is widely used for wastewater treatment rather than for microalgal biomass production [20]. In electrolytic flotation, gas bubbles are formed through electrolysis. Because of the use of electricity, this method is very energy-intensive. For dispersed air flotation, either foam flotation, large bubbles $(1 \mathrm{~mm})$ moving through porous media or froth flotation, a combination of agitation and air injection, are applied [18]. If small bubbles are required, the energy usage for the flotation processes will be very high, which inevitably results in high operational costs and therefore a required high investment. The costs can be even greater when the costs of flocculants are included. Moreover, information and 
evidence are very limited to show that flotation methods are technically or economically feasible [14]. In summary, flotation methods are limited in technical and economic viability.

\subsection{Centrifugation}

In the centrifugal separation process, a much greater force replaces gravity as the force dividing separation. The force applied in this process may be from 4000 to 14,000 times gravitational force. Various centrifugal methods have been applied for microalgae separation, such as tubular centrifuge, multi-chamber centrifuges, imperforate basket centrifuge, decanter, solid retaining disc centrifuge, nozzle type centrifuge, solid ejecting-type disc centrifuge, and hydro-cyclone [18]. It was reported that microalgal pastes with higher solid contents $(>15 \%)$ were harvested through centrifugation methods than by use of other methods [21]. Moreover, some studies revealed that microalgal recovery could be very high $(>90 \%)$ when higher centrifugation speeds were applied [22]. Although centrifugation is a very efficient cell harvesting method for microalgae, it is obvious that the process is energy-intensive. High capital and operational costs, and potentially higher maintenance requirements are the main disadvantages of this process [23-25].

\subsection{Sedimentation}

Gravity sedimentation is a common harvesting method for algae biomass in wastewater treatment. This method is based on Stoke's Law [Equation (2)], which determines the characteristics of suspended solid by density, radius, and sedimentation velocity of algae cells [26]. Stoke's Law can only be used for non-flocculated particles and is not applicable for flocculated particles because of the complicated structure of the flocs [18]:

$$
v=\frac{2}{9} r^{2} g \frac{\rho_{p}-\rho_{f}}{\eta}
$$

where:

$v$ particle settling velocity $(\mathrm{m} / \mathrm{s})$;

$r \quad$ cell radius $(\mathrm{m})$;

g gravitational acceleration $(9.81)\left(\mathrm{m} / \mathrm{s}^{2}\right)$;

$\rho_{p} \quad$ mass density particle $\left(\mathrm{kg} / \mathrm{m}^{3}\right)$;

$\rho_{f}$ mass density fluid $\left(\mathrm{kg} / \mathrm{m}^{3}\right)$;

$\eta \quad$ dynamic viscosity $\left(\mathrm{N} \mathrm{s} / \mathrm{m}^{2}\right)$.

Although this method is considered as a low-cost, simple technique because there are no extra forces other than gravity, the method is only suitable for large microalgae ( $>70 \mu \mathrm{m})$, such as Spirulina [27]. Therefore, for microalgae with a smaller size, chemical flocculation is needed for gravity sedimentation in order to enable the harvesting of algae [18].

\subsection{Flocculation}

It is widely known that most microalgae have negatively charged cell surfaces. This charge is caused by the ionization of ionogenic functional groups on the microalgal cell walls and also by the 
adsorption of ions from the culture medium. Algal species, the ionic strength of medium, $\mathrm{pH}$, and other environmental conditions all have a great impact on the development of this property $[18,28,29]$. This negative charge of the cell surface is important for microalgae growth, especially for preventing the natural aggregation of suspended cells [23].

The surface charge of microalgae cells is also considered as an important property for harvesting microalgae. Neutralizing and reducing microalgal surface charge by applying positively charged electrodes and cationic polymers is commonly performed to flocculate the microalgal biomass. Some multivalent salts, such as ferric chloride $\left(\mathrm{FeCl}_{3}\right)$, aluminum sulfate $\left[\mathrm{Al}_{2}\left(\mathrm{SO}_{4}\right)_{3}\right]$, and ferric sulfate $\left[\mathrm{Fe}_{2}\left(\mathrm{SO}_{4}\right)_{3}\right]$, have been widely used as flocculants and coagulants [23,30]. Some studies also reported that the flocculation of microalgal biomass could be carried out by adjusting the $\mathrm{pH}$ and by simple electrolysis [31,32].

Since this harvesting method produces toxic waste and is relatively expensive because of the cost of flocculants, inexpensive and nontoxic flocculants should be considered for future flocculation processes. In addition, increased efficiency and the use of a lower concentration of flocculants are also very important in order to reduce the harvesting cost [23].

While flocculation is used to harvest small-sized microalgae cells, it is a preparatory step to aggregate the microalgae cells and to increase the particle size so that other harvesting methods such as filtration, centrifugation, or gravity sedimentation can be applied [23]. Several flocculants have been developed to facilitate the aggregation of microalgae cells, including multivalent metal salts such as ferric chloride $\left(\mathrm{FeCl}_{3}\right)$, aluminium sulphate $\left[\mathrm{Al}_{2}\left(\mathrm{SO}_{4}\right)_{3}\right]$, and ferric sulphate $\left[\mathrm{Fe}_{2}\left(\mathrm{SO}_{4}\right)_{3}\right]$, and organic polymers such as chitosan and modified starch [33]. Chemical flocculation can be reliably used to remove small algae cells from pond water by forming large (1-5 mm) sized flocs [34]. However, besides the high cost of chemical flocculants and possible pollution effects that may generate, the chemical reactions are highly sensitive to $\mathrm{pH}$ and the high doses of flocculants required produce large amounts of sludge and may leave a residue in the treated effluent.

\subsection{Filtration}

Some types of filtration systems have been used for microalgae harvesting, such as filter presses, vibrating screens, micro-strains, belt filters, and vacuum drums [35]. Membrane pore size is the most important component that is used to classify filtration systems. Filtration systems can be classified as macro-filtration (pore size of $>10 \mu \mathrm{m}$ ), micro-filtration (pore size of $0.1-10 \mu \mathrm{m}$ ), ultra-filtration (pore size of $0.02-2 \mu \mathrm{m}$ ), and reverse osmosis (pore size of $<0.001 \mu \mathrm{m}$ ). In most cases, pressure is needed to force the liquid through the membrane and thus accelerate the water removal [36].

Macro-filtration is the most appropriate method for larger microalgae $(>70 \mu \mathrm{m})$, such as Coelastrum and Spirulina. Micro-filtration and ultra-filtration are widely used for the recovery of smaller microalgae cells $(<30 \mu \mathrm{m})$. Ultra-filtration is suitable for fragile cells because it requires low transmembrane pressure and low cross-flow velocity conditions. Even so, ultra-filtration has not generally been used because operating and maintenance costs are high [1,14,35,37].

Membrane filtration can be more cost-effective for low broth volumes $\left(<2 \mathrm{~m}^{3}\right)$. However, in large-scale production $\left(>20 \mathrm{~m}^{3}\right)$, this method will be less effective because of the costs of the membrane and the energy needed [23]. It was also found that for large-scale and high-density algae cultivation, cell packing 
could be a significant problem with this method. Although stirring and shaking can offer a solution to this problem, a lot of energy is needed for this process, especially for a large amount of liquid [38].

Most conventional and economical separation methods such as filtration and gravitational sedimentation are widely applied in wastewater treatment facilities to harvest relatively large ( $>70 \mathrm{~mm})$ microalgae, such as Coelastrum and Spirulina. However, they cannot be used to harvest algae species approaching bacterial dimensions $(<30 \mathrm{~mm})$, such as Scenedesmus, Dunaliella and Chlorella [14], to which most oleaginous microalgae species belong. Centrifugation is widely used to recover microalgae biomass, especially small-sized algae cells; however, its application is restricted to algae cultures for high-value metabolites due to intensive energy needs and high equipment maintenance requirements.

In addition to these traditional methods just presented are several new technology developments in this field. The U.S. Department of Energy Advanced Research Projects Agency-Energy (DOE-ARPA-E) recently funded a research project for Algae Venture Systems (AVS) to develop a Harvesting, Dewatering and Drying (HDD) technology by using the principles of liquid adhesion and capillary action to extract water from dilute microalgae solutions. Attached algal culture systems have been developed for growing microalgae on the surface of polystyrene foam to simplify the cell harvest $[39,40]$. New bioflocculants, which are more environmentally friendly, are also proposed to address the cost and environmental concerns for current flocculation methods [41]. Cell pellets of filamentous fungi Aspergillus flavus were applied as a biological flocculation agent to harvest the microalgae cells. These pellets need to be prepared by fungal cultivation with sugar medium; they can then absorb the microalgae cells into the pellet structure due to the surface charge difference [42]. These methods are innovative and will decrease the harvest cost to some extent if developed successfully; however, they require heavy investments on equipment and chemical supplies.

Enhancing natural algae aggregation to encourage simple gravity settling or filtration appears to be the most promising option to achieve both a high-quality treated effluent, in terms of total suspended solids, and an economic recovery of algal biomass for biofuel use [41]. It will also be more environmentally sound than current procedures, which may need chemical additives. Many of the algal species in the wastewater treatment processes often form large colonies (50-200 mm), and their cell aggregation can be achieved through nitrogen limitation and $\mathrm{CO}_{2}$ addition [17]; however, most of these microalgae species are not oleaginous species. Methods to enable oleaginous microalgae aggregate during their cultivation are strategically and urgently needed to develop efficient and economic means of biofuel production.

\section{Fugal Pelletization}

Filamentous fungi can have various morphologies in submerged cultures, depending on the organism and on the operative culture conditions [43]. The morphologies include: dispersed hyphae, microscopic aggregates, loose hyphal aggregates, which are commonly referred to as clumps, and denser spherical aggregates, commonly referred to as pellets [44]. Filamentous organisms have the common feature hyphae, which is a polarized pattern in the form of filaments. These hyphal elements originate from the outgrowth of single cells or spores as multinucleate tubes containing cytoplast, which moves within a hypha toward the hyphal tip. The hyphal tip is the only place where the hypha grows. 
From the main hyphae, new tips are formed, which produce branches, resulting in a network of hyphae, termed mycelia [45,46]. Mycelial growth can be divided into microscopic and macroscopic morphology $[47,48]$.

\subsection{Microscopic Morphology}

The growth of fungi will begin with a single spore or several spores. Without supplying nutrients necessary for activation, the spores will remain inactive. By absorbing much water in the early phase of the germination process, the spores extend in an isotropic manner [49]. In the early phase of cultivation, the microscopic morphology of filamentous fungi can be described by two important parameters, namely the total hyphal length $L(\mu \mathrm{m})$, which is obtained by summing up all hyphae in a mycelium, and the number of tips $n(-)[50,51]$. These parameters can be determined through digital image analysis.

Kinetically, the exponential growth of mycelia can be described by a specific length growth rate $\mu\left(\mathrm{h}^{-1}\right)[52]$ :

$$
\frac{d L}{d t}=\mu \cdot L
$$

In general, mycelial growth is composed of an increase in the length of each tip and an increase of the number of tips produced by branching. With $q_{\text {tip }}\left(\mu \mathrm{m} \mathrm{h}^{-1}\right)$ being a constant tip growth rate of $n$ tip, the total hyphal length growth can be determined [52]:

$$
\frac{d L}{d t}=q_{t i p} \cdot n
$$

It was found that the blanching process relied on mycelial length, which has been regarded as a branching constant $k_{\text {bran }}\left(\mu \mathrm{m}^{-1} \mathrm{~h}^{-1}\right)$ [52]:

$$
\frac{d n}{d t}=k_{\text {bran }} \cdot L
$$

An essential relationship between tip growth and hyphal branching is described as hyphal growth unit $(H G U)$, which is the average length of each tip in a mycelium [52]:

$$
H G U=\frac{L}{n}
$$

$H G U$ increases during the first stage of mycelial growth until a steady state is reached. Consequently, the amount of hyphal tips starts increasing exponentially $[53,54]$.

\subsection{Macroscopic Morphology and Pelletization of Filamentous Fungi}

The final micromorphology of filamentous fungi is determined by several factors such as the properties of the strain, and the applied cultivation conditions (e.g., inoculum properties, mechanical stress, temperature, medium composition and $\mathrm{pH}$ ) [55]. The morphological processes and other physicochemical environmental treatments result in the apparent macro-morphology that is known by the size and the structure of the growth form [48]. Depending on the operating conditions, some filamentous fungi may form pellets when they are grown submerged. These fungal cell pellets are spherical or ellipsoidal masses of hyphae with variable internal structures, varying significantly from a very loose and irregular form to a compact and spherical form [5,50,56-59]. Based on their 
structure, pellets can be classified into three groups: (a) fluffy, loose pellets, in which the center of the pellets is compact and the outer zone is much looser; (b) compact smooth pellets, in which the whole pellet is compact and the outside of the pellet is smooth; and (c) hollow smooth pellets, in which the center of the pellet is hollow due to autolysis and the outside is smooth [50].

Numerous studies on pellets have already been carried out. In terms of pellet formation, filamentous fungi can form pellets in two ways, namely non-coagulative formation and coagulative formation. For the non-coagulating type, pellets are formed out of one spore. This type of pellet formation has been reported for some actinomycetes from the genus Streptomyces [45,60] and for fungi belonging to Rhizopus spp. and Mucor spp. [50]. In coagulating pellet formation, the spores usually aggregate in the early stage of cultivation and pellets are formed out of these aggregates. This type of pellet formation can include Aspergillus nidulans, Aspergillus niger, Aspergillus oryzae, and the basidiomycete fungus Phanerochaete chrysosporium [45,50,52]. For example, Aspergillus niger, a common filamentous fungus that has been studied extensively, gives a clear image of the microscopic morphology that is related to the formation of the pellets [52]. After inoculation, the aggregation of conidia begins immediately and keeps steady during the first stage of cultivation. In this stage, $\mathrm{pH}$ values strongly affect the process. A second aggregation step is triggered by the germination process and the hyphal growth of germ tubes, which increase the hyphal surface area to which conidia can attach. In the final growth stage, pellet formation begins after the second aggregation $[47,52]$.

It has been observed that the structure and formation of pellets is determined by many different factors. Microbiological factors, including genetics, cell wall composition, inoculum size, growth rate, nutrition, and the carbon nitrogen ratio $(\mathrm{C} / \mathrm{N}$ ratio) and physicochemical factors including share forces, surface active agents, $\mathrm{pH}$, temperature, $\mathrm{Ca}^{2+}$ ion, ionic strength, and suspended solids have been found to impact the structure and formation of pellets [61]. However, many studies revealed that the structural properties and the pelletization process are very strongly dependent on cultivation conditions $[46,50]$.

\subsection{Application of Pelletized Growth on Microbial Oil Accumulation}

The research group at University of Minnesota applied the pelletized fungal fermentation (PLF) to microbial oil production and developed methods to induce pellet formation during their cell growth [5]. In addition to merits from the cell immobilization, other advantages for the micro-oil production include the ease of harvesting cells and of re-using pond water $[5,40]$. The research results showed that conditions for cell pelletization seem to be strain-specific and that not all the filamentous fungal strains can form pellets during their growth. With induction of $\mathrm{CaCO}_{3}$ powder in the early stage of its cultivation, cell pellets can be formed homogeneously, lasting for the entire cultivation cycle for M. circillenous (Figure 1). The research also found that changing conditions, for example, $\mathrm{pH}$ adjustment during cell cultivation, can induce fungal cells to aggregate and form pellets. This method avoids traditional approaches that use $\mathrm{CaCO}_{3}$ powder to induce the fungal pelletization, which are costly and cause solid waste disposal issues [59,62]. 
Figure 1. Pelletization of Mucor circinelloides: (a) by adding $\mathrm{CaCO}_{3}$; and (b) by only adjusting $\mathrm{pH}$ during cell growth [5].

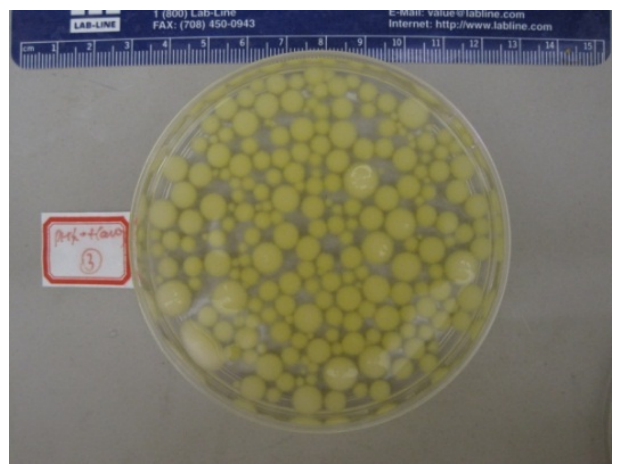

(a)

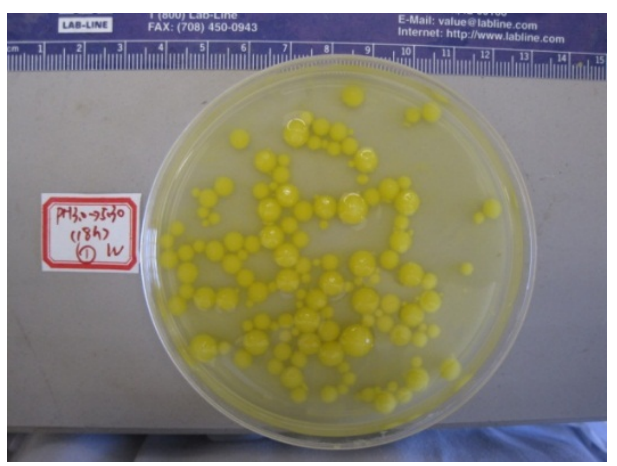

(b)

This pelletization strategy was applied to the culture of $M$. circillenous with sulfuric acid hydrolyzed corn stover solution (Figure 2). With sulfuric acid pretreatment, the liquid solution generated from the corn stover contains a diluted concentration of sugars (predominantly xylose) and various types of chemical by-products that may have inhibitive effects on many fermentation processes (e.g., baker's yeast). Because the sugar solution is so diluted, resulting in low concentrations of cell cultures that are also difficult to harvest, using any type of cell cultures for microbial oil accumulation will be economically unfeasible. By inoculating spores of $M$. circillenous into this solution and using our pelletization strategy to induce the cell pelletization as shown in Figure 2, it was found that self-aggregated pelletization dramatically improved mass transfer and cell cultivation performance and facilitated cell harvest and separation. A simple filtration can be used to separate the cell biomass from the fermentation broth. This approach has tremendous advantages to decrease the harvest cost of biofuel production, particularly in cases for which sugar sources are diluted and final cell concentration is low.

Figure 2. Application of pelletized filamentous fungal fermentation.

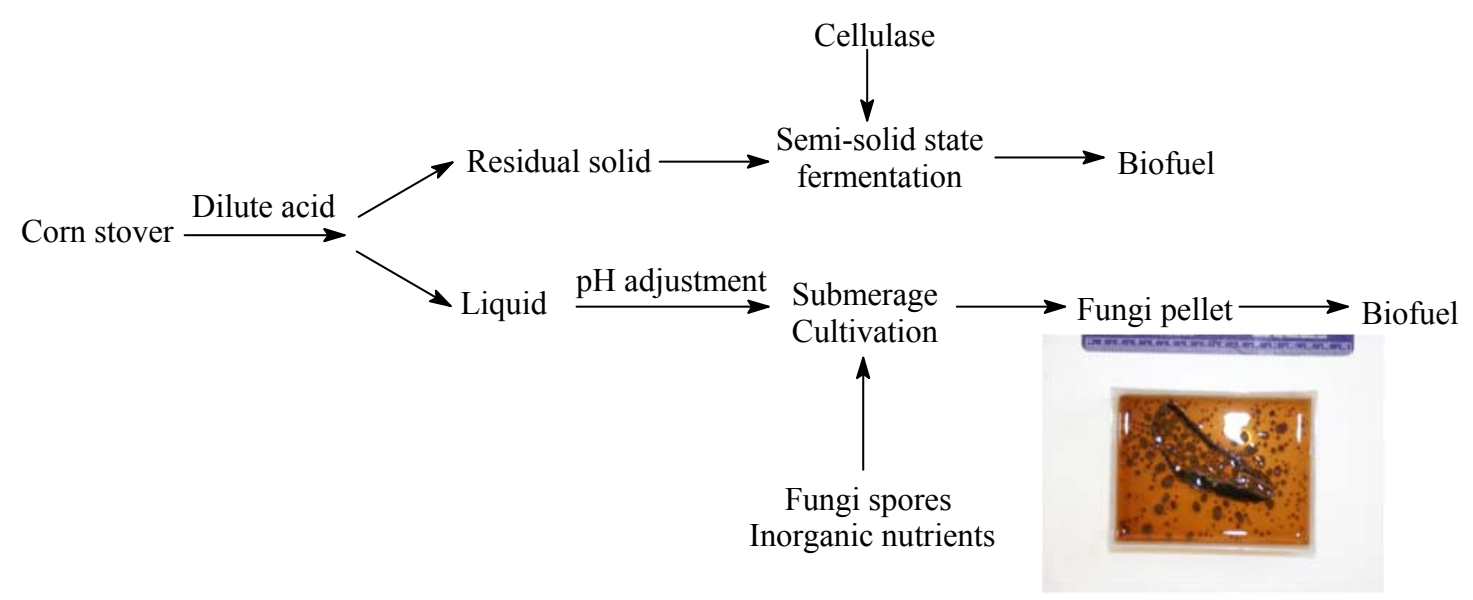

\section{Pelletization of Filamentous Fungi on Harvesting Microalgae Cells}

Pelletization is more widely seen in the fungal fermentation process, in which the microorganisms are filamentous. However, most oleaginous microalgae are not filamentous and oleaginous microalgae 
pelletization has not been seen in a complete review of current literature. The research group at University of Minnesota conducted a study to inoculate filamentous fungal spores when culturing mixotrophic green algae $C$. vulguris and found that pellets clearly formed within two days of culture $[63,64]$. The algae solution lost most of its green color, and turned transparent, indicating the majority of microalgae cells were pelletized (Figure 3). As seen in the image captured via microscope, the skeleton structure of the pellet was still filamentous fungal cells. The microalgae cells, aggregated together with fungal cells, were immobilized in the pellets. This result can be developed into an innovative technology uniquely addressing the cell harvest of microalgae and has the potential to greatly reduce the algae biofuel cost. It is a transformative method that can be applied to different microalgae and fungal strains, although the operational conditions may vary across strain combinations. This concept and design can be transformative to other microalgae cultures and can be applied not only in the microbial oil production, but also in processes of wastewater treatment to remove nutrients [65], bioremediation for pollutant chemicals and heavy metals, value added products generated by microalgal cultures and other areas.

Figure 3. Pelletization of Chlorella vulguris with assistance from filamentous fungi [63,64].
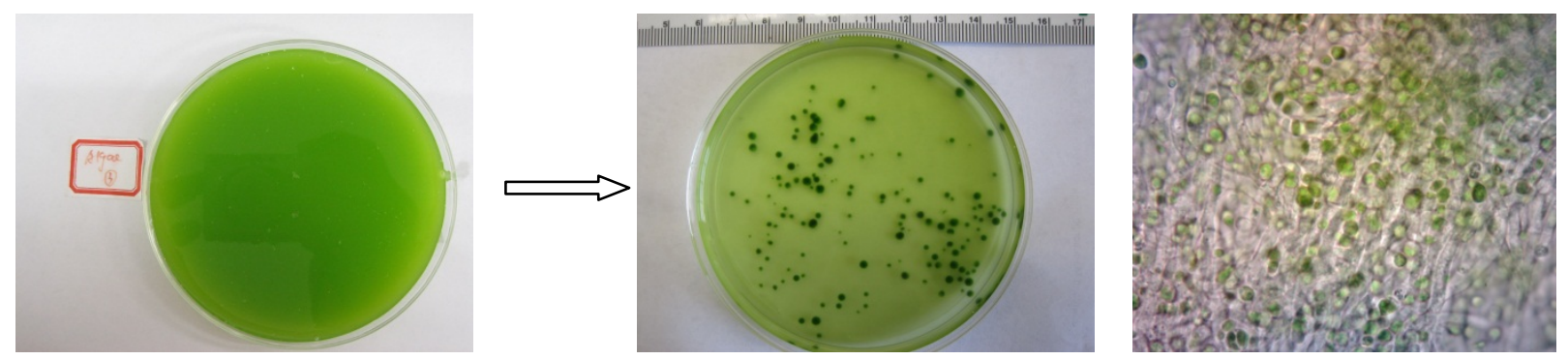

The study in 2012 by Zhang and $\mathrm{Hu}$ [66] showed that twelve filamentous fungi cultured together with microalgae, seven fungi formed green-colored pellets instead of milky white-colored pellets. This finding indicated that some microalgal cells attached to or were entrapped in the pellets. Several fungal species, such as ATCC 11730 and RLG 9902, can form pellets that can entrap all of the individual microalgae cells, resulting in a completely clear co-culture broth of those strains (Table 1). For M. circinelloides (Table 1) and A. oryzae, however, some C. vulgaris cells remain in the supernatant.

Table 1. Photos of co-pellets of fungal species and Chlorella vulgaris [63,64].

\begin{tabular}{|c|c|c|c|c|c|}
\hline Fungal species & M. isabellina & M. circinelloides & RLG 9902 & Ted S-OSU & ATCC 9642 \\
\hline Fungal pellets & & & & 8 & \\
\hline Co-pellets & No pellets & & & & \\
\hline
\end{tabular}

Another similar study carried out by Zhou et al. [67] found that the filamentous fungus Aspergillus orizae, which was isolated from municipal wastewater sludge, could be used to assist in 
the harvesting process of microalgal cells. The microalgae cells, aggregated together with fungal cells, were immobilized in the pellets. Results showed that $\mathrm{pH}$ was the key factor affecting the formation of these algae-fungal pellets, which is similar to the previous conclusion that $\mathrm{pH}$ serviced as the key factor to induce the pelletization of $M$. circillenous alone [5]. This similar research was also published in a poster, which reviewed that three commercially interesting algal species (Chlorella vulgaris, Chlorella sorokiniana and Scenedesmus vacuolatus) were investigated for their compatibility with a previously uncharacterized Sordariomycete to form pellets, which the researchers claim as a symbiotic lichen structure [68].

\subsection{Mechanism of Fungal Algae Co-Pelletization}

The fungi/algae copelletization process can be considered as a type of co-culture where the filamentous fungi co-exist with the microalgae. If the microalgae are under autotrophic growth mode and the filamentous fungi rely on the microalgae to grow (no external sugar added to the system), this algae-fungal pellet system will function as lichens, where fungi and autotrophic algae co-exist in the matrixes structure and form a symbiosis system. More than one-fifth of all extant fungal species are known to be lichenized, living in a close (obligate) mutualistic association with photoautotrophic green algae, cyanobacteria, or both types of photobionts [69]. They have successfully adapted to life under harsh conditions. However, natural fungal/algae ecosystems, such as lichens, despite their high ecological importance, are not of central interest in a scientific and engineering community, where rapid growth and high yields are needed [70]. The production of the autotrophic algae biomass was significantly improved when inoculating the filamentous fungus and being pelletized indicated some mutual stimulation of cell growth of both strains [66], but detailed research is needed to consider this algae/fungal co-pellets system as a simulated lichen system and study the interactions between fungi and algae cells. This research focus will provide a unique understanding to improve the design of the system so that eventually it can be applied industrial systems. Rather than using gene modification to synthesize multiple functions within one model microorganism, it is technically promising to mix different cell populations to construct a synthetic lichen system and use it as the basis of a model for the robustness and boundary parameters of such systems. The potential advantage of microbial consortia (or multicultures) compared with monocultures is two-fold. First, in contrast to monocultures, multicultures allow different species to share the various required synthetic functions. This function sharing significantly decreases the cell metabolism burden. Second, the sharing of different functions potentially renders microbial consortia more suited for the fine-tuning of their artificial functionality [71,72]. This increased suitability is especially true for most current algae and fungal cell cultivation because gene-modification of microalgae and fungi is technically difficult.

The fungal/algae co-pelletization process is also similar to the current flocculation process in which fungal hyphae serve as the flocculants and the attraction between fungal and algae cells can possible be explained through the zeta potential at each cell surface. According to Shelef et al. [18], the surface charge and the cell size and density were the main factors for the stability of microalgae suspension in the culture. In term of surface charge, it was reported that at neutral $\mathrm{pH}$, microalgae reveal a slightly negative charge because of the presence of proton-active carboxylic, phosphoric, phosphodiester, hydroxyl, and amine functional groups $[23,73]$. The zeta potential of microalgae is typically negative 
and is generally within the range from $-10 \mathrm{mV}$ to $-35 \mathrm{mV}$ [74]. Measurements of zeta potential on fungus Beauveria bassiana strains showed that the surface charge of aerial conidia differed depending on the age of the spores. Results showed that 16-day aerial conidia displayed the highest positive zeta potential $(22 \pm 2 \mathrm{mV})$ at low $\mathrm{pH}(\mathrm{pH} \mathrm{3})$, which rapidly became negative by $\mathrm{pH} 5$, reaching a net negative surface charge of $230 \pm 4 \mathrm{mV}$ at $\mathrm{pH} 8-9$ [75]. In a similar published research study [42], A. flavus pellets were used to absorb the microalgae cells, and their zeta-potential measurement revealed the average potential for microalgae as $-23.7 \mathrm{mV}$ and A. flavus as $+46.1 \mathrm{mV}$. The charge difference between the microalgae and fungal cells indicated the capability of $A$. flavus to capture microalgae, and it may also provide some clue that surface charge might be the reason for the co-pelletization of microalgae and fungal cells.

It is unclear how the use of fungi for pelletization is fundamentally different or superior to the use of bacteria for bioflocculation - and bioflocculation is not a new concept $[35,76]$. As a matter of fact, bacteria, which can generate bioflocculant chemicals, have been studied to harvest microalgae as well as other photosynthetic cells $[77,78]$. Bacteria can make up to $30 \%$ of the biomass in the photic zone of open waters, and a large proportion of the mixed micro-algal biomass grown in wastewater [35]. Recent research found that the microalgae associated bacteria played a profound role in flocculating by increasing the floc size resulting in the sedimentation of microalgae [79]. Bio-flocculants produced from bacteria have been shown to be effective in the flocculation of Chlorella [23]. The algae/bacteria floc was directly utilized to treat wastewater as well as possibly generating biofuel. These similar results can be taken as references for future direction on the fungal algae pelletization research. Also, the procedure difference between the co-pelletization of algae/fungi and the flocculation lies in the flocculants where the flocculation agents are generated from chemical/biological conversion processes separately while co-pelletization process seems to integrate the two steps by generating fungal cells during the algae cell culture. Which way is superior is undetermined.

\subsection{Impact on Subsequent Downstreaming Processing of Microalgae Cells}

Although the detailed co-pelletization methods have been described by different researchers, how the co-cultured pellets would affect downstream processing, including extraction of lipids, conversion to fuels, and utilization of lipid extracted algae/fungi for co-products are not substantially elucidated yet. The choice of fungal strains will be the key because it determines the overall pelletization efficiency, and it will also have direct impact on the subsequent processes.

For the autotrophic microalgae cultivation, no external sugar was added to support the germination and growth of $A$. niger, therefore, the fungal cells must grow on the carbons generated by microalgae cells [66]. What chemicals are supporting the fungal growth needs to be determined. Many researchers confirmed that $A$. niger can produce different degradation enzymes during their cell growth and the enzyme is excreted in the fermentation broth to degrade the polysaccharide to support the cell growth [80]. Adding external cellulase to the culture of $C$. vulgaris showed a significant increase in sugar concentration. Other researchers also confirmed this result that external cellulase can be added to the microalgae cultures to hydrolyze the polysaccharides within the microalgae cell walls in order to generate free sugars for bioethanol fermentation [81]. The composition varies among microalgae strains, but cellulose is reported as the main structural component of the cell wall for many microalgae species 
(up to $70 \%$ by dry weight for $C$. vulgaris). It is possible that fungi were utilizing algae to grow and the detailed mechanism needs to be determined. In this case, fungal strains that can generate certain hydrolysis enzymes will be the ideal candidates and their effects on the microalgae growth need to be determined.

The competition of nutrients between fungi and microalgae is believed to occur mostly in the heterotrophic growth mode where microalgae need to rely on external carbon sources to support their growth. This competition may also occur at autotrophic conditions where other nutrients, for example, organic nitrogen, are limited. In context of competition of nutrients, neither fungi nor microalgae cells will reach to their maximized growth compared with their growth in the pure culture of these strains individually. Meanwhile, the question of "Who wins?" will be the research target that needs to be answered to provide information on the applications when population control of an individual strain is needed. In this case, it will be ideal to choose the fungal strains as oleaginous if the aim of the process is to generated microbial lipids.

No matter what kind of fungal strains being selected, the fungal biomass will for sure affect the existing extraction methods as well as the value of the extraction leftover for co-product use, such as animal feed. Detailed research is missing here. Fungal cells contain numerous types of polysaccharide, for instance, chitin, on their cell biomass and have well-known capability of moisture preservation, and co-culturing with fungi cells may increase the difficulty for the subsequent drying of algae biomass [82]. Research finding was published on use of external cellulase on the microalgae biomass in order to hydrolyze the cell wall and facilitate the lipid extraction, therefore, it is possible that the lipid extraction may be improved with co-culture of enzyme producing fungi $[83,84]$. The lipid extraction from fungal cells may be very different the one from algae cells due to the different cell compositions, therefore, it may complicate the overall lipid extraction process also. Many fungal strains generate certain toxins, especially aflatoxin commonly produced by Aspergillus flavus and other strains, which may cause serious concerns if the biomass leftover is deemed as feeding materials [85].

\subsection{Economic Feasibility and Scale-Up}

The detailed economic analysis of this technology is not yet complete. To compare between this method and chemical flocculation, different chemical flocculants may have different prices and dosage. On the general dosage, chemicals should be much more expensive than inoculation of fungal spores. However, a techno-economic analysis is needed to include the nutrients supplements for fungal growth, especially when some methods involved $20 \mathrm{~g} / \mathrm{L}$ glucose as needed for growth of pellets [65]. It is not clear whether co-culturing fungal cells will affect the growth and nutrient assimilation of microalgae. It will be economically unfeasible if high concentration of sugars is needed just to grow the fungal cells. A life cycle assessment will evaluate the impact of this technology on the economics of co-culturing these species (i.e., nutrient requirements) as well as the entire algae to biofuels value chain (added cost and energy requirements/benefits for downstream processing and co-product use). Fungal culture, if strains are biologically safe, does not cause any secondary pollution issue while chemical flocculants may have over dosage and remain as pollutants in the water [35]. 
Of course, current studies are still primarily on the lab and scaling-up of the co-pelletization process using the optimum conditions found in the laboratory study will also be needed in order to make this method more economically attractive and viable to the industry.

\section{Conclusions}

Fungal/algae co-pelletization is a promising technology for microalgae harvesting, which may possibly be used as an alternative to decrease the capital and operational costs. Optimum conditions in the lab scale have been described in recent studies by various research groups, while detailed study is still needed to understand the mechanisms, the impact on subsequent steps, and the economic feasibility of this process.

\section{Conflicts of Interest}

The authors declare no conflict of interest.

\section{References}

1. Borowitzka, M.A. Commercial production of microalgae: Ponds, tanks, tubes and fermenters. J. Biotechnol. 1999, 70, 313-321.

2. Miao, X.; Wu, Q. Biodiesel production from heterotrophic microalgal oil. Bioresour. Technol. 2006, 97, 841-846.

3. Chisti, Y. Biodiesel from microalgae. Biotechnol. Adv. 2007, 25, 294-306.

4. Tsukahara, K.; Sawayama, S. Liquid fuel production using microalgae. J. Jpn. Pet. Inst. 2005, $48,251-259$.

5. Xia, C.; Zhang, J.; Zhang, W.; Hu, B. A new cultivation method for microbial oil production: Cell pelletization and lipid accumulation by Mucor circinelloides. Biotechnol. Biofuels 2011, 4, doi:10.1186/1754-6834-4-15.

6. Fakas, S.; Papanikolaou, S.; Batsos, A.; Galiotou-Panayotou, M.; Mallouchos, A.; Aggelis, G. Evaluating renewable carbon sources as substrates for single cell oil production by Cunninghamella echinulata and Mortierella isabellina. Biomass Bioenergy 2009, 33, 573-580.

7. Heredia-Arroyo, T.; Wei, W.; Ruan, R.; Hu, B. Mixotrophic cultivation of Chlorella vulgaris and its potential application for the oil accumulation from non-sugar materials. Biomass Bioenergy 2011, 35, 2245-2253.

8. Yang, C.; Hua, Q.; Shimizu, K. Energetics and carbon metabolism during growth of microalgal cells under photoautotrophic, mixotrophic and cyclic light-autotrophic/dark-heterotrophic conditions. Biochem. Eng. J. 2000, 6, 87-102.

9. Wang, B.; Li, Y.; Wu, N.; Lan, C.Q. $\mathrm{CO}_{2}$ bio-mitigation using microalgae. Appl. Microbiol. Biotechnol. 2008, 79, 707-718.

10. Benemann, J.R. $\mathrm{CO}_{2}$ mitigation with microalgae systems. Energy Convers. Manag. 1997, 38, S475-S479. 
11. Zeiler, K.G.; Heacox, D.A.; Toon, S.T.; Kadam, K.L.; Brown, L.M. The use of microalgae for assimilation and utilization of carbon-dioxide from fossil fuel-fired power-plant flue-gas. Energy Convers. Manag. 1995, 36, 707-712.

12. Mosojídek, J.; Torzillo, G.; Sven Erik, J.; Brian, F. Mass Cultivation of Freshwater Microalgae. In Encyclopedia of Ecology; Academic Press: Oxford, UK, 2008; pp. 2226-2235.

13. Liang, Y.N.; Sarkany, N.; Cui, Y. Biomass and lipid productivities of Chlorella vulgaris under autotrophic, heterotrophic and mixotrophic growth conditions. Biotechnol. Lett. 2009, 31, 1043-1049.

14. Brennan, L.; Owende, P. Biofuels from microalgae-A review of technologies for production, processing, and extractions of biofuels and co-products. Renew. Sustain. Energy Rev. 2010, 14, $557-577$.

15. Wu, Q.; Xiong, W. Method for Producing Biodiesel from an Alga. U.S. Patent 2009/0298159A1, 3 December 2009.

16. Olaizola, M. Commercial development of microalgal biotechnology: From the test tube to the marketplace. Biomol. Eng. 2003, 20, 459-466.

17. Park, J.B.K.; Craggs, R.J.; Shilton, A.N. Wastewater treatment high rate algal ponds for biofuel production. Bioresour. Technol. 2011, 102, 35-42.

18. Shelef, G.; Sukenik, A.; Green, M. Microalgae Harvesting and Processing: A Literature Review; Technion Research and Development Foundation Ltd.: Haifa, Israel, 1984.

19. Edzwald, J.K. Algae, bubbles, coagulants, and dissolved air flotation. Water Sci. Technol. 1993, $27,67-81$.

20. Christenson, L.; Sims, R. Production and harvesting of microalgae for wastewater treatment, biofuels, and bioproducts. Biotechnol. Adv. 2011, 29, 686-702.

21. Sim, T.S.; Goh, A.; Becker, E.W. Comparison of centrifugation, dissolved air flotation and drum filtration techniques for harvesting sewage-grown algae. Biomass 1988, 16, 51-62.

22. Heasman, M.; Diemar, J.; O’Connor, W.; Sushames, T.; Foulkes, L. Development of extended shelf-life microalgae concentrate diets harvested by centrifugation for bivalve molluscs - A summary. Aquac. Res. 2000, 31, 637-659.

23. Molina Grima, E.; Belarbi, E.-H.; Acién Fernández, F.G.; Robles Medina, A.; Chisti, Y. Recovery of microalgal biomass and metabolites: Process options and economics. Biotechnol. Adv. 2003, 20, 491-515.

24. Bosma, R.; van Spronsen, W.A.; Tramper, J.; Wijffels, R.H. Ultrasound, a new separation technique to harvest microalgae. J. Appl. Phycol. 2003, 15, 143-153.

25. Shen, Y.; Yuan, W.; Pei, Z.J.; Wu, Q.; Mao, E. Microalgae mass production methods. Trans. ASABE 2009, 52, 1275-1287.

26. Schenk, P.M.; Thomas-Hall, S.R.; Stephens, E.; Marx, U.C.; Mussgnug, J.H.; Posten, C.; Kruse, O.; Hankamer, B. Second generation biofuels: High-efficiency microalgae for biodiesel production. Bioenergy Res. 2008, 1, 20-43.

27. Munoz, R.; Guieysse, B. Algal-bacterial processes for the treatment of hazardous contaminants: A review. Water Res. 2006, 40, 2799-2815.

28. Ives, K.J. The significance of surface electric charge on algae in water purification. J. Biochem. Microbiol. Technol. Eng. 1959, 1, 37-47. 
29. Golueke, C.G.; Oswald, W.J. Harvesting and processing sewage-grown planktonic algae. J. Water Pollut. Control Fed. 1965, 37, 471-498.

30. Koopman, B.; Lincoln, E.P. Autoflotation harvesting of algae from high-rate pond effluents. Agric. Wastes 1983, 5, 231-246.

31. Wu, Z.; Zhu, Y.; Huang, W.; Zhang, C.; Li, T.; Zhang, Y.; Li, A. Evaluation of flocculation induced by $\mathrm{pH}$ increase for harvesting microalgae and reuse of flocculated medium. Bioresour. Technol. 2012, 110, 496-502.

32. Poelman, E.; De Pauw, N.; Jeurissen, B. Potential of electrolytic flocculation for recovery of micro-algae. Resour. Conserv. Recycl. 1997, 19, 1-10.

33. Li, Y.; Horsman, M.; Wu, N.; Lan, C.Q.; Dubois-Calero, N. Biofuels from microalgae. Biotechnol. Prog. 2008, 24, 815-20.

34. Sharma, B.R.; Dhuldhoya, N.C.; Merchant, U.C. Flocculants-An ecofriendly approach. J. Polym. Environ. 2006, 14, 195-202.

35. Milledge, J.J.; Heaven, S. A review of the harvesting of micro-algae for biofuel production. Rev. Environ. Sci. Biotechnol. 2013, 12, 165-178.

36. Jaouen, P.; Vandanjon, L.; Quéméneur, F. The shear stress of microalgal cell suspensions (Tetraselmis suecica) in tangential flow filtration systems: The role of pumps. Bioresour. Technol. 1999, 68, 149-154.

37. Rossignol, N.; Vandanjon, L.; Jaouen, P.; Quéméneur, F. Membrane technology for the continuous separation microalgae/culture medium: Compared performances of cross-flow microfiltration and ultra-filtration. Aquac. Eng. 1999, 20, 191-208.

38. Morris, I.; Yentsch, C.S. A new method for concentrating phytoplankton by filtration with continuous stirring. Limnol. Oceanogr. 1972, 17, 490-493.

39. Wilkie, A.C.; Mulbry, W.W. Recovery of dairy manure nutrients by benthic freshwater algae. Bioresour. Technol. 2002, 84, 81-91.

40. Johnson, M.B.; Wen, Z.Y. Development of an attached microalgal growth system for biofuel production. Appl. Microbiol. Biotechnol. 2010, 85, 525-534.

41. Uduman, N.; Qi, Y.; Danquah, M.K.; Forde, G.M.; Hoadley, A. Dewatering of microalgal cultures: A major bottleneck to algae-based fuels. J. Renew. Sustain. Energy 2010, 2, doi:10.1063/1.3294480.

42. Rajab, A.H. Micro-Algae Removal in Domestic Wastewater Using Aspergillus Flavus Soft Pellets as a Bio-Coagulant. Ph.D. Thesis, Universiti Putra Malaysia, Selangor, Malaysia, 2007.

43. Gibbs, P.A.; Seviour, R.J.; Schmid, F. Growth of filamentous fungi in submerged culture: Problems and possible solutions. Crit. Rev. Biotechnol. 2000, 20, 17-48.

44. Cox, P.W.; Paul, G.C.; Thomas, C.R. Image analysis of the morphology of filamentous micro-organisms. Microbiology 1998, 144, 817-827.

45. Znidarsic, P.; Pavko, A. The morphology of filamentous fungi in submerged cultivations as a bioprocess parameter. Food Technol. Biotechnol. 2001, 39, 237-252.

46. Zmak, P.M.; Podgornik, A.; Podgornik, H.; Koloini, T. Impact of pellet size on growth and lignin peroxidase activity of Phanerochaete chrysosporium. World J. Microbiol. Biotechnol. 2006, 22, 1243-1249. 
47. Krull, R.; Cordes, C.; Horn, H.; Kampen, I.; Kwade, A.; Neu, T.R.; Nortemann, B. Morphology of Filamentous Fungi: Linking Cellular Biology to Process Engineering Using Aspergillus niger. In Biosystems Engineering II: Linking Cellular Networks and Bioprocesses; Wittmann, C., Krull, R., Eds.; Springer: Heidelberg, Germany, 2010; Volume 121, pp. 1-21.

48. Krull, R.; Wucherpfennig, T.; Esfandabadi, M.E.; Walisko, R.; Melzer, G.; Hempel, D.C.; Kampen, I.; Kwade, A.; Wittmann, C. Characterization and control of fungal morphology for improved production performance in biotechnology. J Biotechnol. 2013, 163, 112-123.

49. Osherov, N.; May, G.S. The molecular mechanisms of conidial germination. FEMS Microbiol. Lett. 2001, 199, 153-160.

50. Metz, B.; Kossen, N.W.F. The growth of molds in the form of pellets-A literature review. Biotechnol. Bioeng. 1977, 19, 781-799.

51. Trinci, A.P. A study of the kinetics of hyphal extension and branch initiation of fungal mycelia. J. Gen. Microbiol. 1974, 81, 225-236.

52. Grimm, L.H.; Kelly, S.; Hengstler, J.; Gobel, A.; Krull, R.; Hempel, D.C. Kinetic studies on the aggregation of Aspergillus niger conidia. Biotechnol. Bioeng. 2004, 87, 213-218.

53. Bergter, F. Kinetic-model of mycelial growth. Z. Allg. Mikrobiol. 1978, 18, 143-145.

54. Prosser, J.I.; Trinci, A.P. A model for hyphal growth and branching. J. Gen. Microbiol. 1979, 111, 153-164.

55. Papagianni, M.; Stanhope, R. Should serum IGF-I concentrations be monitored routinely during growth hormone therapy? J. Pediatr. Endocrinol. Metab. 2004, 17, 141-142.

56. Hu, B.; Chen, S.L. Biological hydrogen production using chloroform-treated methanogenic granules. Appl. Biochem. Biotechnol. 2008, 148, 83-95.

57. Hu, B.; Chen, S.L. Pretreatment of methanogenic granules for immobilized hydrogen fermentation. Int. J. Hydrog. Energy 2007, 32, 3266-3273.

58. Hu, B.; Zhou, X.; Forney, L.; Chen, S.L. Changes in microbial community composition following treatment of methanogenic granules with chloroform. Environ. Prog. Sustain. Energy 2009, 28, $60-71$.

59. Liao, W.; Liu, Y.; Chen, S.L. Studying pellet formation of a filamentous fungus Rhizopus oryzae to enhance organic acid production. Appl. Biochem. Biotechnol. 2007, 137, 689-701.

60. Vecht-Lifshitz, S.E.; Magdassi, S.; Braun, S. Pellet formation and cellular aggregation in Streptomyces tendae. Biotechnol. Bioeng. 1990, 35, 890-896.

61. Braun, S.; Vechtlifshitz, S.E. Mycelial morphology and metabolite production. Trends Biotechnol. 1991, 9, 63-68.

62. Liu, Y.; Liao, W.; Chen, S. Co-production of lactic acid and chitin using a pelletized filamentous fungus Rhizopus oryzae cultured on cull potatoes and glucose. J. Appl. Microbiol. 2008, 105, $1521-1528$.

63. Xia, C.; Zhang, J.; Hu, B. Microbial Oil Accumulation via Pelletized Cultivation of Mucor Circinelloides. In Proceedings of the 33rd Symposium on Biotechnology for Fuels and Chemicals, Seattle, WA, USA, 2-5 May 2011.

64. Zhang, J.G.; Hu, B. A Novel Method to Harvest Microalgae via Fungal Pelletization. In Proceedings of the AIChE Annual Meeting, Minneapolis, MN, USA, 16-21 October 2011. 
65. Zhou, W.G.; Cheng, Y.L.; Li, Y.; Wan, Y.Q.; Liu, Y.H.; Lin, X.Y.; Ruan, R. Novel fungal pelletization-assisted technology for algae harvesting and wastewater treatment. Appl. Biochem. Biotechnol. 2012, 167, 214-228.

66. Zhang, J.G.; Hu, B. A novel method to harvest microalgae via co-culture of filamentous fungi to form cell pellets. Bioresour. Technol. 2012, 114, 529-535.

67. Zhou, W.G.; Min, M.; Hu, B.; Ma, X.C.; Liu, Y.H.; Wang, Q.; Shi, J.; Chen, P.; Ruan, R. Filamentous fungi assisted bio-flocculation: A novel alternative technique for harvesting heterotrophic and autotrophic microalgal cells. Sep. Purif. Technol. 2013, 107, 158-165.

68. Mackay, S.; Pereira Gomes, E.; Rossi, P.; Schwitzguebel, J.-P.; Holliger, C. Pelletization of Micro-Algae by Induced Lichen Formation through Co-Culture with Filamentous Fungi. In Proceedings of the SME 2013 5th Swiss Microbial Ecology Meeting, Murten, Switzerland, 4-6 February 2013.

69. Zoller, S.; Lutzoni, F. Slow algae, fast fungi: Exceptionally high nucleotide substitution rate differences between lichenized fungi Omphalina and their symbiotic green algae Coccomyxa. Mol. Phylogenet. Evol. 2003, 29, 629-640.

70. Honegger, R. Functional-aspects of the lichen symbiosis. Annu. Rev. Plant Physiol. Plant Mol. Biol. 1991, 42, 553-578.

71. Biliouris, K.; Babson, D.; Schmidt-Dannert, C.; Kaznessis, Y.N. Stochastic simulations of a synthetic bacteria-yeast ecosystem. BMC Syst. Biol. 2012, 6, doi:10.1186/1752-0509-6-58.

72. Mee, M.T.; Wang, H.H. Engineering ecosystems and synthetic ecologies. Mol. Biosyst. 2012, 8, 2470-2483.

73. Hadjoudja, S.; Deluchat, V.; Baudu, M. Cell surface characterisation of Microcystis aeruginosa and Chlorella vulgaris. J. Colloid Interface Sci. 2010, 342, 293-299.

74. Henderson, R.K.; Parsons, S.A.; Jefferson, B. Successful removal of algae through the control of zeta potential. Sep. Sci. Technol. 2008, 43, 1653-1666.

75. Holder, D.J.; Kirkland, B.H.; Lewis, M.W.; Keyhani, N.O. Surface characteristics of the entomopathogenic fungus Beauveria (Cordyceps) bassiana. Microbiology 2007, 153, 3448-3457.

76. Olguin, E.J. Dual purpose microalgae-bacteria-based systems that treat wastewater and produce biodiesel and chemical products within a biorefinery. Biotechnol. Adv. 2012, 30, 1031-1046.

77. Van den Hende, S.; Vervaeren, H.; Desmet, S.; Boon, N. Bioflocculation of microalgae and bacteria combined with flue gas to improve sewage treatment. New Biotechnol. 2011, 29, 23-31.

78. Xie, G.J.; Liu, B.F.; Xing, D.F.; Nan, J.; Ding, J.; Ren, N.Q. Photo-fermentative bacteria aggregation triggered by L-cysteine during hydrogen production. Biotechnol. Biofuels 2013, 6, doi:10.1186/1754-6834-6-64.

79. Lee, J.; Cho, D.H.; Ramanan, R.; Kim, B.H.; Oh, H.M.; Kim, H.S. Microalgae-associated bacteria play a key role in the flocculation of Chlorella vulgaris. Bioresour. Technol. 2013, 131, 195-201.

80. Acharya, P.B.; Acharya, D.K.; Modi, H.A. Optimization for cellulase production by Aspergillus niger using saw dust as substrate. Afr. J. Biotechnol. 2008, 7, 4147-4152.

81. Harun, R.; Danquah, M.K. Enzymatic hydrolysis of microalgal biomass for bioethanol production. Chem. Eng. J. 2011, 168, 1079-1084.

82. Wittenberg, K.M. Preservation of high-moisture hay in storage through the use of forage additives. Can. J. Anim. Sci. 1991, 71, 429-437. 
83. Yin, L.J.; Jiang, S.T.; Pon, S.H.; Lin, H.H. Hydrolysis of Chlorella by Cellulomonas sp. YJ5 cellulases and its biofunctional properties. J. Food Sci. 2010, 75, H317-H323.

84. Fu, C.-C.; Hung, T.-C.; Chen, J.-Y.; Su, C.-H.; Wu, W.-T. Hydrolysis of microalgae cell walls for production of reducing sugar and lipid extraction. Bioresour. Technol. 2010, 101, 8750-8754.

85. Mehl, H.L.; Jaime, R.; Callicott, K.A.; Probst, C.; Garber, N.P.; Ortega-Beltran, A.; Grubisha, L.C.; Cotty, P.J. Aspergillus flavus diversity on crops and in the environment can be exploited to reduce aflatoxin exposure and improve health. Annu. N. Y. Acad. Sci. 2012, 1273, 7-17.

(C) 2013 by the authors; licensee MDPI, Basel, Switzerland. This article is an open access article distributed under the terms and conditions of the Creative Commons Attribution license (http://creativecommons.org/licenses/by/3.0/). 